\title{
PENENTUAN STATUS MUTU AIR TANAH DANGKAL DI SEKITAR TEMPAT PEMBUANGAN AKHIR SAMPAH (TPA) AIR SEBAKUL KOTA BENGKULU MENGGUNAKAN METODE STORET: A CROSS-SECTIONAL STUDY
}

\author{
Deni Agus Triawan ${ }^{1,2^{*}}$, Doni Notriawan ${ }^{2}$, Gustria Ernis ${ }^{2}$ \\ ${ }^{1}$ Jurusan Kimia Fakultas Matematika dan Ilmu Pengetahuan Alam Universitas Bengkulu \\ ${ }^{2}$ Program Studi D3 Laboratorium Sains Fakultas Matematika dan Ilmu Pengetahuan Alam \\ Universitas Bengkulu \\ *email:deni.agustriawan@unib.ac.id,deni_agust@ymail.com
}

Received 02 January 2020

Accepted 14 May 2020

\begin{abstract}
Abstrak
Kualitas air tanah memiliki peranan yang sangat penting untuk air minum, sanitasi dan domestik. Penelitian ini bertujuan untuk mengetahui kualitas air tanah di sekitar TPA Air Sebakul Kota Bengkulu dengan menentukan beberapa parameter kualitas air seperti $\mathrm{pH}$, TDS (padatan terlarut), daya hantar listrik, salinitas, besi (Fe), mangan $(\mathrm{Mn})$, nitrat $\left(\mathrm{NO}_{3}{ }^{-}\right)$ dan nitrit $\left(\mathrm{NO}_{2}^{-}\right)$. Pengambilan sampel dilakukan pada radius $0-250$ meter dari lokasi TPA pada sampel air sumur gali dan air sumur bor masyarakat. Hasil pengukuran $\mathrm{pH}$ pada 10 titik sampling menunjukkan nilai yang cukup bervariasi dengan kisaran 6,45 - 7,59; konduktivitas antara $56-492 \mu \mathrm{S}$ dan TDS antara $28-246 \mathrm{mg} / \mathrm{L}$; kesadahan berkisar antara $32-284 \mathrm{mg} / \mathrm{L}$; Fe antara 0,040 - 0,323 mg/L; Mn antara 0,089 - 0,295 mg/L; Nitrat antara 0,2 - 0,8 mg/L (bakumutu $10 \mathrm{mg} / \mathrm{L}$ ) dan Nitrit antara 0,006 - 0,033 mg/L (bakumutu $1 \mathrm{mg} / \mathrm{L}$ ). Berdasarkan penilaian dengan sistem STORET, status mutu air di wilayah studi tergolong baik (skor $=-4$ ) berdasarkan 10 parameter (suhu, TDS, DHL, bau, rasa, $\mathrm{pH}$, kesadahan, Fe, Mn, Nitrat dan Nitrit). Berdasarkan informasi tersebut, air tanah dangkal di sekitar TPA Air Sebakul Kota Bengkulu dapat digunakan untuk keperluan hygiene sanitasi.
\end{abstract}

Kata kunci: Air tanah, metode STORET, parameter fisika dan kimia

\begin{abstract}
Ground Water quality has a special significance for drinking, hygiene sanitation and domestic water supply. The study aims to understand the distribution of ground water quality in solid waste landfill of Bengkulu City. The following objectives of the study are to determine ground water quality parameters such as $\mathrm{pH}$, total dissolved solid, electrical conductivity, hardness, iron, manganese, nitrate and nitrite. Sampling was carried out at a radius of $0-250$ meters from the location of the landfill. The results of the $\mathrm{pH}$ at 10 sampling points show the values that are quite varied between $6,45-7,59$; conductivity between $56-492 \mu \mathrm{S}$; TDS between $28-246 \mathrm{mg} / \mathrm{L}$; salinity $32-284 \mathrm{mg} / \mathrm{L}$; Iron $(\mathrm{Fe})$ $0,040-0,323 \mathrm{mg} / \mathrm{L}$; Manganese $(\mathrm{Mn}) 0,089-0,295 \mathrm{mg} / \mathrm{L}$; Nitrate $\left(\mathrm{NO}_{3}{ }^{-}\right)$0,2 - 0,8 mg/L and Nitrite $\left(\mathrm{NO}_{2}{ }^{-}\right) 0,006-0,033 \mathrm{mg} / \mathrm{L}$. Based on an assessment with the STORET system, water quality in the study area is classified as good (score $=-4$ ) by parameters such as temperature, $\mathrm{pH}$, total dissolved solid, electrical conductivity, hardness, iron, manganese, nitrate and nitrite. By the total sampling sites, all sample site had good-quality water for hygiene sanitation based on STORET method.
\end{abstract}

Keywords: Ground Water, STORET method, physical and chemical parameter. 


\section{Pendahuluan}

Air tanah merupakan suatu sumber alam yang dapat diperbaharui yang bersifat terbatas dan perlu peran sangat penting dalam penyediaan air bersih untuk berbagai keperluan (Ambica, 2014; Jha, 2018). Dengan adanya penggunaan lahan di permukaan tanah sebagai tempat pembuangan akhir sampah, areal yang dekat dengan tempat pembuangan sampah akan berpotensi lebih tinggi untuk mengalami penurunan kualitas air tanah yang disebabkan oleh penyerapan (infiltrasi) berbagai zat pencemar ke dalam tanah yang dapat menurunkan kualitas air tanah (Jha, 2017).

Salah satu cara untuk mengontrol penurunan kualitas air tanah dapat dilakukan dengan pemantauan kualitas air tanah dalam jangka waktu tertentu, sehingga diketahui kondisi perairan tersebut. Jika terjadi perubahan kualitas air, segera dilakukan pencegahan dan penanggulangan sehingga tidak menimbulkan pencemaran lebih lanjut (Akter et al., 2016).

Salah satu metode monitoring kualitas air adalah penggunaan metode STORET (Barokah et al., 2017; Shik et al., 2015; Triawan et al., 2018). Penentuan status mutu air dengan metode STORET dapat digunakan sebagai acuan dalam melakukan pemantauan kualitas air tanah dengan tujuan untuk mengetahui mutu (kualitas) suatu sistem perairan (Menteri Negara Lingkungan Hidup, 2003).

Penentuan status mutu air didasarkan pada analisis parameter fisika dan kimia air seperti $\mathrm{pH}$, Total Dissolved Solid (TDS), konduktivitas, salinitas, nitrat dan nitrit (Jha, 2017). Parameter tersebut dipilih berdasarkan faktor penyebab penurunan kualitas air. Pengambilan contoh air dilakukan di RT. 24 RW. 04 Kelurahan Sukarami Kecamatan Selebar Kota Bengkulu dengan menggunakan metode stratified disproportional random sampling. Pengambilan sampel dengan cara ini dimaksudkan agar setiap lokasi terwakili oleh beberapa sampel sehingga keseluruhan sampel untuk penentuan status mutu air tanah dangkal di sekitar TPA Air Sebakul Kota Bengkulu dapat diketahui.

\section{Metode Penelitian}

Penelitian dilakukan dengan metode deskriptif kuantitatif yaitu melakukan pengukuran terhadap parameter kualitas air dengan mengambil secara acak (randomly) 10 titik air tanah dangkal dari sumur masyarakat (sumur gali dan sumur bor) yang terbagi pada radius sampai 250 $\mathrm{m}$ dari lokasi TPA Air Sebakul Kota Bengkulu. Sampel S1 sampai S8 merupakan sumur gali, sedangkan sampel S9 dan S10 merupakan sumur bor dengan kedalaman \pm 60 meter (Tabel 1).

Tabel 1. Rincian lokasi sampling

\begin{tabular}{lcl}
\hline No & Kode Sampel & $\begin{array}{c}\text { Lokasi (Radius } \\
\text { dari lokasi TPA) }\end{array}$ \\
\hline $\mathbf{1}$ & S1-S3 & Radius 0-50 m \\
\hline $\mathbf{2}$ & S4-S6 & Radius 50-100 m \\
\hline $\mathbf{3}$ & S7-8 & Radius 100-250 m \\
\hline $\mathbf{4}$ & S9-S10 & Sumur bor \\
\hline
\end{tabular}

\section{Alat dan Bahan}

Peralatan yang digunakan pada penelitian ini1111 adalah $\mathrm{pH}$ meter, TDS \& EC meter (Kedida CT-6022), Salinometer (Kedida CT-3080), Atomic Absorption Spectroscopy (AAS) (Aligent 200 Series AA), Spektrofotometer UVVis (Agilent Cary 60).

\section{Prosedur Penelitian}

Penelitian dimulai dengan pengambilan sampel sesuai dengan lokasi yang sudah ditetapkan. Beberapa parameter seperti $\mathrm{pH}$, Zat Padat Terlarut (TDS), Daya Hantar Listrik (DHL), dan salinitas diukur secara langsung di lapangan. Sementara parameter $\mathrm{Fe}, \mathrm{Mn}$, Nitrat dan Nitrit diukur di laboratorium yang terakreditasi. Pengukuran $\mathrm{Fe}$ menggunakan Spektroskopi Serapan Atom (SSA) dengan metode SNI 066989.4-2004 sedangkan pengukuran $\mathrm{Mn}$ dengan metode SNI 06-6989.5-2004. 
Pengukuran Nitrat menggunakan Spektrofotometer sesuai dengan SNI6989-79-2011 dan Nitrit sesuai dengan SNI 06-6989.9-2004.

\section{Analisis Data}

Analisis data statistik deskriptif digunakan untuk menganalisis rata-rata, nilai tengah, standar deviasi dan frekuensi dari masing-masing parameter. Evaluasi kualitas air dilakukan dengan membandingkan hasil analisis dengan baku mutu yang ditetapkan pemerintah RI melalui PermenKes Nomor 32 tahun 2017 tentang standar baku mutu kesehatan lingkungan dan persyaratan kesehatan air untuk keperluan higiene sanitasi, kolam renang, solus per aqua, dan pemandian umum (PerMenKes, 2017).

\section{Status Mutu Air berdasarkan Metode Storet}

Metode STORET merupakan salah satu metode untuk menentukan status mutu air yang umum digunakan (Barokah et al., 2017; Triawan et al., 2018). Dengan metode STORET ini dapat diketahui tingkatan klasifikasi mutu parameter yang memenuhi atau telah melampaui bakumutu air. Penentuan status mutu air ini berdasarkan pada analisis parameter fisika, kimia maupun biologi. Kualitas air yang baik akan sesuai dengan peraturan yang dikeluarkan pemerintah tersebut dengan kadar (konsentrasi) yang diperbolehkan (Menteri Negara Lingkungan Hidup, 2003). Pada penelitian ini, penentuan status mutu air berdasarkan sistem STORET dengan cara membandingkan hasil pengukuran dari masing-masing parameter air dengan nilai bakumutu berdasarkan PermenLH Nomor 32 tahun 2017.

Jika hasil pengukuran memenuhi nilai baku mutu air (hasil pengukuran s bakumutu) diberi skor 0. Jika hasil pengukuran tidak memenuhi nilai bakumutu air (hasil pengukuran > baku mutu) maka diberi skor (Tabel 2. Jumlah negatif dari seluruh parameter dihitung dan ditentukan status mutu airnya dengan menggunakan sistem nilai.

Tabel 2. Penentuan sistem nilai untuk menentukan status mutu air

\begin{tabular}{clccc}
\hline \multirow{2}{*}{$\begin{array}{c}\text { Jumlah } \\
\text { contoh }^{1)}\end{array}$} & \multirow{2}{*}{ Nilai } & \multicolumn{3}{c}{ Parameter } \\
\cline { 3 - 5 }$<10$ & Maksimum & -1 & -2 & -3 \\
& Minima & Kimia & Biologi \\
\hline & Rata-rata & -1 & -2 & -3 \\
\hline \multirow{2}{*}{$\geq 10$} & Maksimum & -2 & -6 & -9 \\
& Minimum & -2 & -4 & -6 \\
& Rata-rata & -6 & -12 & -18 \\
\hline
\end{tabular}

Sumber: KermenLH No. 115 Tahun 2003

Catatan ${ }^{1)}$ jumlah paremeter yang digunakan untuk penentuan status mutu air

Kualitas air dinilai berdasarkan ketentuan sistem STORET yang dikeluarkan oleh EPA (Environmental Protection Agency) yang mengklasifikasikan mutu air ke dalam empat kelas, yaitu:

1. Kelas A : baik sekali, skor $=0$ memenuhi bakumutu

2. Kelas B : baik, skor $=-1 \mathrm{~s} / \mathrm{d}-10$ cemar ringan

3. Kelas C : sedang, skor $=-11 \mathrm{~s} / \mathrm{d}-30$ cemar sedang

4. Kelas D : buruk, skor lebih dari -31 cemar berat

\section{Hasil dan Pembahasan}

\section{Parameter Fisika-Kimia Air}

Hasil pengukuran suhu sampel air tidak memperlihatkan variasi yang besar, bahkan relatif stabil yaitu berkisar antara 27,6-29, $8^{\circ} \mathrm{C}$ (Gambar 1). Suhu air mempunyai peranan dalam mengatur kehidupan biota perairan terutama dalam proses metabolisme, kenaikan suhu menyebabkan terjadinya peningkatan konsumsi oksigen. Pengukuran $\mathrm{pH}$ pada saat pengambilan sampel terlihat bahwa pada 10 sampel air bervariasi dengan kisaran 6,45 - 7,59 (Gambar 2). Nilai derajat keasaman ini berada diluar batas $\mathrm{pH}$ yang diperbolehkan yaitu 6,0-9,0. 


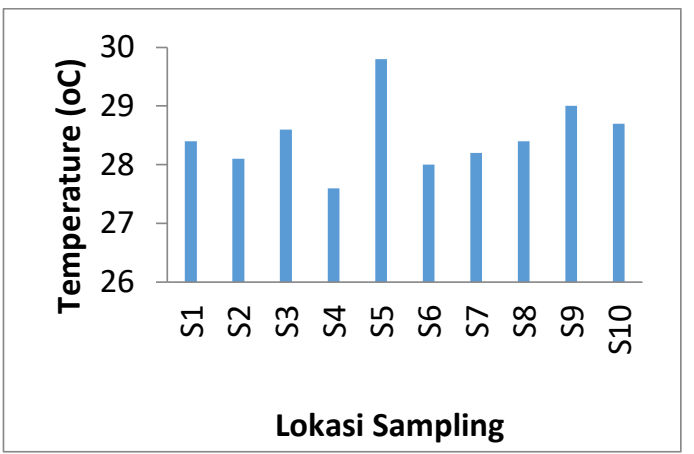

Gambar 1. Suhu air pada berbagai lokasi sampling

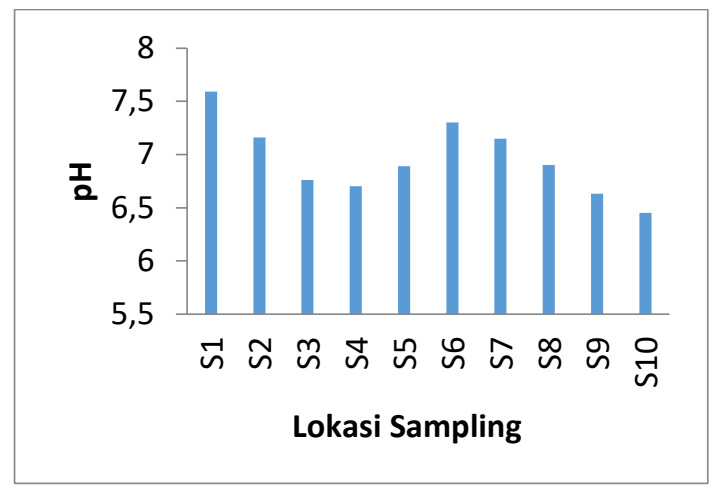

Gambar 2. pH air pada berbagai lokasi sampling

Hasil pengukuran konduktivitas pada 10 titik sampling menunjukkan nilai yang cukup bervariasi antara $56-492 \mu \mathrm{S}$ (Gambar 4) dengan TDS antara 28 - 246 $\mathrm{mg} / \mathrm{L}$ (Gambar 3). Nilai TDS yang cukup tinggi ditemukan pada lokasi sampling Air Sumur Bor dengan nilai TDS masingmasing $246 \mathrm{mg} / \mathrm{L}$ dan $189 \mathrm{mg} / \mathrm{L}$. Air yang memiliki nilai TDS ataupun konduktivitas yang tinggi menunjukkan bahwa terdapat banyak ion di dalamnya terlarut di dalamnya yang dapat disebabkan oleh adanya pelarutan mineral dari batuan pada kedalaman tertentu (Harter, 2003). Namun, nilai ini masih berada dibawah ambang batas yang diperbolehkan berdasarkan PermenKes No. 32 tahun 2017 sebesar 1000 mg/L untuk keperluan Higiene Sanitasi. Salinitas air pada lokasi sampling berkisar antara $32-284 \mathrm{mg} / \mathrm{L}$ (Gambar 5). Nilai salinitas yang cukup tinggi ditemukan di Air Sumur Bor I dan II dengan nilai sebesar $284 \mathrm{mg} / \mathrm{L}$ dan 262 $\mathrm{mg} / \mathrm{L}$. Nilai ini sebanding dengan naiknya nilai TDS dan konduktivitas air. Nilai maksimum kesadahan menurut PermenKes No. 32 tahun 2017 sebesar $500 \mathrm{mg} / \mathrm{L}$.

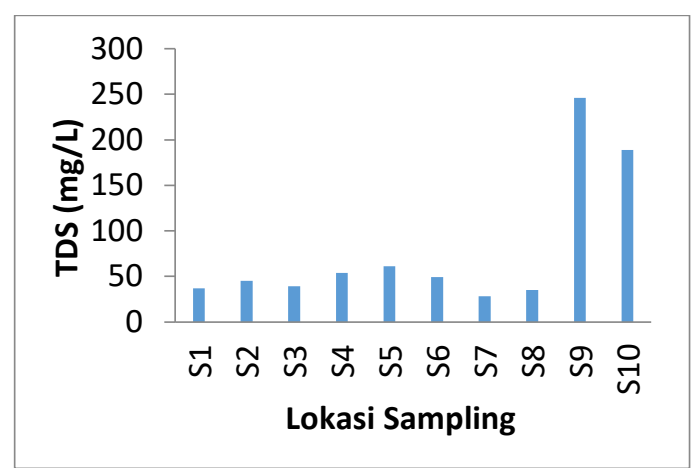

Gambar 3. TDS air pada berbagai lokasi sampling

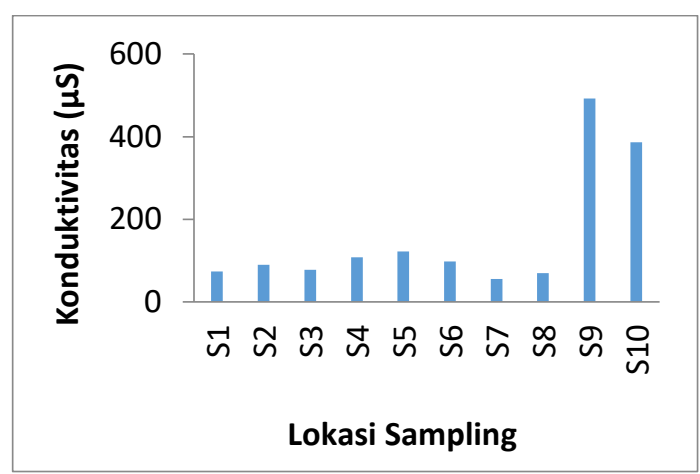

Gambar 4. EC air pada berbagai lokasi sampling

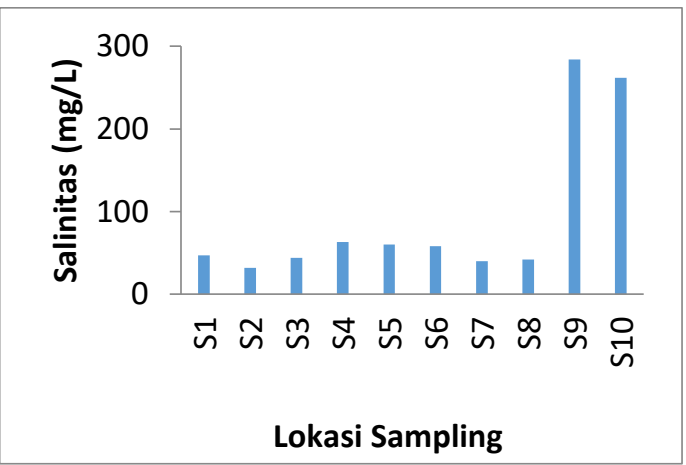

Gambar 5. Salinitas air pada berbagai lokasi sampling

Parameter logam yang diamati berupa Fe dengan nilai antara $0,040-0,323$ $\mathrm{mg} / \mathrm{L}$. Sedangkan parameter logam yang lain yang dianalisis adalah Mn dengan nilai antara 0,089-0,295 mg/L. Kadar Fe dan Mn ini cukup tinggi namun masih memenuhi baku mutu sebesar $1 \mathrm{mg} / \mathrm{L}(\mathrm{Fe})$ 
dan baku mutu sebesar $0,5 \mathrm{mg} / \mathrm{L}(\mathrm{Mn})$. Tingginya konsentrasi Mn dapat menyebabkan air menimbulkan rasa, warna (coklat/hitam dan meningkatkan kekeruhan). Bagi kesehatan, konsentrasi mangan $>0,5 \mathrm{mg} / \mathrm{L}$ menyebabkan air bersifat neurotoksik dengan gejala yang yang timbul seperti gangguan susunan syaraf, insomnia, lemah pada kaki dan otot (Febrina and Ayuna, 2015).

Paremeter nitrat dan nitrit yang teramati di wilayah studi cukup bervariasi dengan nilai nitrat antara $0,2-0,8 \mathrm{mg} / \mathrm{L}$ (bakumutu $10 \mathrm{mg} / \mathrm{L}$ ) dan nitrit antara $0,006-0,033 \mathrm{mg} / \mathrm{L}$ (bakumutu $1 \mathrm{mg} / \mathrm{L}$ ). Air tanah dangkal dapat terkontaminasi oleh nitrit disebabkan adanya limbah organik manusia seperti kotoran tinja sampah. Air sumur yang dekat dengan septic tank berpotensi memiliki kandungan nitrat dan nitrit yang lebih tinggi (Setiowati et al., 2016). Secara keseluruhan, nilai nitrat dan nitrit Air Tanah dangkal di sekitar TPA Kota Bengkulu masih tergolong rendah dan masih memenuhi bakumutu yang ditetapkan berdasarkan PermenKes No. 32 tahun 2017 untuk keperluan hygiene Sanitasi.

\section{Status Mutu Air}

Berdasarkan penilaian dengan sistem STORET, status mutu air di wilayah studi tergolong baik (skor $=-4$ ) berdasarkan 10 parameter (suhu, TDS, DHL, bau, rasa, pH, kesadahan, Fe, Mn, Nitrat dan Nitrit) (Tabel 3). Parameter yang mempengaruhi kondisi penurunan kualitas air tejadi pada pH. Sedangkan parameter salinitas tergolong tinggi (mencapai $284 \mathrm{mg} / \mathrm{L}$ ) namun masih dibawah baku mutu yang ditetapkan pemerintah yaitu sebesar 500 $\mathrm{mg} / \mathrm{L}$. Secara umum, air tanah dangkal di sekitar TPA Air Sebakul Kota Bengkulu dapat digunakan untuk keperluan hygiene sanitasi untuk pemeliharaan kebersihan perorangan seperti mandi dan sikat gigi, serta untuk keperluan cuci bahan pangan, peralatan makan, dan pakaian (Kementerian Kesehatan Republik Indonesia, 2017).

Tabel 3. Status mutu air di wilayah studi

\begin{tabular}{|c|c|c|c|c|c|c|}
\hline \multirow[b]{2}{*}{ Parameter } & \multirow{2}{*}{$\begin{array}{l}\text { Baku } \\
\text { mutu }\end{array}$} & \multirow[b]{2}{*}{ Satuan } & \multicolumn{3}{|c|}{ Hasil Pengukuran } & \multirow[b]{2}{*}{ Skor } \\
\hline & & & Max & Min & $\begin{array}{l}\text { Rata- } \\
\text { Rata }\end{array}$ & \\
\hline \multicolumn{7}{|l|}{ FISIKA } \\
\hline Suhu & \pm 3 & ${ }^{\circ} \mathrm{C}$ & 29,8 & 27,6 & 28,7 & 0 \\
\hline $\begin{array}{l}\text { TDS (Zat Padat } \\
\text { Terlarut) }\end{array}$ & 1000 & $\mathrm{mg} / \mathrm{L}$ & 246 & 28 & 137 & 0 \\
\hline Daya Hantar Listrik & - & & 492 & 54 & 274 & 0 \\
\hline Bau & $\begin{array}{l}\text { tidak } \\
\text { berbau }\end{array}$ & & $\begin{array}{c}\text { tidak } \\
\text { berbau }\end{array}$ & $\begin{array}{c}\text { tidak } \\
\text { berbau }\end{array}$ & $\begin{array}{c}\text { tidak } \\
\text { berbau }\end{array}$ & 0 \\
\hline Rasa & $\begin{array}{l}\text { tidak } \\
\text { berasa }\end{array}$ & & $\begin{array}{c}\text { tidak } \\
\text { berasa }\end{array}$ & $\begin{array}{c}\text { tidak } \\
\text { berasa }\end{array}$ & $\begin{array}{l}\text { tidak } \\
\text { berasa }\end{array}$ & 0 \\
\hline \multicolumn{7}{|l|}{ KIMIA } \\
\hline $\mathrm{pH}$ & $6,5-8,5$ & & 7,59 & 6,45 & 7,02 & -4 \\
\hline Kesadahan & 500 & $\mathrm{mg} / \mathrm{L}$ & 421 & 52 & 221,96 & 0 \\
\hline $\mathrm{Fe}(\mathrm{Besi})$ & 1 & $\mathrm{mg} / \mathrm{L}$ & 0,323 & 0,040 & 0,182 & 0 \\
\hline Mn (Mangan) & 0.5 & $\mathrm{mg} / \mathrm{L}$ & 0,295 & 0,089 & 0,192 & 0 \\
\hline NO3-N (Nitrat) & 10 & $\mathrm{mg} / \mathrm{L}$ & 0,8 & 0,2 & 0,5 & 0 \\
\hline NO2-N (Nitrit) & 1 & $\mathrm{mg} / \mathrm{L}$ & 0,002 & 0,033 & 0,0195 & 0 \\
\hline JUMLAH SKOR & & & & & & -4 \\
\hline
\end{tabular}




\section{Kesimpulan}

Hasil pengukuran $\mathrm{pH}$ pada 10 titik sampling menunjukkan nilai yang cukup bervariasi dengan kisaran $6,45-7,59$; konduktivitas antara $56-492 \mu \mathrm{S}$ dan TDS antara $28-246 \mathrm{mg} / \mathrm{L}$; kesadahan berkisar antara $32-284 \mathrm{mg} / \mathrm{L} ; \mathrm{Fe}$ antara $0,040-0,323 \mathrm{mg} / \mathrm{L}$; Mn antara 0,089 $0,295 \mathrm{mg} / \mathrm{L}$; Nitrat antara $0,2-0,8 \mathrm{mg} / \mathrm{L}$ (bakumutu $10 \mathrm{mg} / \mathrm{L}$ ) dan Nitrit antara 0,006 - 0,033 mg/L (bakumutu $1 \mathrm{mg} / \mathrm{L}$ ). Berdasarkan penilaian dengan sistem STORET, status mutu air di wilayah studi tergolong baik (skor $=-4$ ) berdasarkan 10 parameter (suhu, TDS, DHL, bau, rasa, $\mathrm{pH}$, kesadahan, Fe, Mn,

\section{Daftar Pustaka}

Akter, T., Jhohura, F.T., Akter, F., Chowdhury, T.R., Mistry, S.K., Dey, D., 2016, Water Quality Index for measuring drinking water quality in rural Bangladesh : a cross- sectional study, J. Heal. Popul. Nutr., 1-12.

Ambica, A., 2014, Ground Water Quality Characteristics Study by Using Water Quality Index in Tambaram Area, Chennai, Tamil Nadu, Middle East Journal of Scientific Research, 20(11), 1396-1401.

Barokah, G.R., Ariyani, F., Siregar, T.H., 2017, Comparison of Storet and Pollution Index Method to Assess the Environmental Pollution Status: A Case Study from Lampung Bay, Indonesia, Squalen Bull. Mar. Fish. Postharvest Biotechnol, 12(2), 6774.

Febrina, L., Ayuna, A., 2015, Studi Penurunan Kadar Besi (Fe) dan Mangan (Mn) dalam Air Tanah Menggunakan Saringan Keramik, $J$. Teknol. Univ. Muhammadiyah Jakarta, 7(1), 5-44.

Harter, T., 2003, Reference: Groundwater Quality and. Nat. Resour. Conserv. Serv. Publicatio, $11,2$.
Nitrat dan Nitrit). Berdasarkan informasi tersebut, air tanah dangkal di sekitar TPA Air Sebakul Kota Bengkulu dapat digunakan untuk keperluan hygiene sanitasi untuk pemeliharaan kebersihan perorangan seperti mandi dan sikat gigi, serta untuk keperluan cuci bahan pangan, peralatan makan, dan pakaian.

\section{Ucapan Terima Kasih}

Penulis mengucapkan terimakasih kepada Universitas Bengkulu yang telah mendanai penelitian ini melalui dana RBA FMIPA 2019 dengan nomor kontrak: $\quad$ 2080/UN30.12/HK/2019.

Jha, A., 2018, Assessment of chemical and microbial contamination of groundwater around pit-latrines - A case study in Dharampur and Dadpur villages of Samastipur District of Bihar Assessment of chemical and microbial contamination of groundwater around pit-latrines - A case study in Dharampur and Dadpur villages of Samastipur District of Bihar, International Journal of Advanced Research, 2(5), 396-401.

Jha, A., 2017, Ground Water Quality Assessment near Municipal Solid Waste Dump Site- a Case Study, Journal of Chemical, Biological and Physical Sciences, 7(1), 14-18.

Menteri Negara Lingkungan Hidup, 2003, Pedoman Penentuan Status Mutu Air Nomor 112, 158-166.

PerMenKes, 2017, Standar Baku Mutu Kesehatan Lingkungan dan Persyaratan Kesehatan Air Untuk Keperluan Higiene Sanitasi, Kolam Renang, Solus Per Aqua dan Pemandian Umum Nomor 32.

Setiowati, Roto, Wahyuni, E.T., 2016, Monitoring Kadar Nitrit dan Nitrat pada Air Sumur di Daerah Catur Tunggal Yogyakarta dengan Metode Spektrofotometri UV-Vis, J. Mns. dan Lingkung., 23, 143-148. 
Shik, Y., Engel, B.A., Kim, J., Theller, L., Chaubey, I., Merwade, V., Jae, K., 2015, A web tool for STORET / WQX water quality data retrieval and Best Management Practice scenario suggestion, J. Environ. Manage, 150, 21-27.
Triawan, D.A., Harlianto, B., Nesbah, 2018, Ground Water Quality Characteristics Study in Coastal Area of Bengkulu City by Using STORET Method: A CrossSectional Study. Proceeding 1st Int. Conf. Chem. Pharm. Med. Sci. Univ. Bengkulu, 27-28 November 2018, 8, 47-51. 